\title{
CALCIUM BUFFERING IS REQUIRED TO MAINTAIN BONE STIFFNESS IN SALINE SOLUTION
}

\author{
M. B. Gustafson, ${ }^{*}$ R. B. Martin, ${ }^{*}$ V. Gibson, ${ }^{*}$ D. H. Storms, $†$ S. M. Stover, $\ddagger$ J. Gibeling§ and L. Griffin§ \\ *Orthopaedic Research Laboratories, School of Medicine; †Department of Environmental Toxicology, College of \\ Agricultural and Environmental Sciences; $\ddagger$ Orthopedic Research Laboratory, School of Veterinary Medicine; and \\ §Department of Chemical Engineering, School of Engineering, University of California at Davis, Davis, CA 95616,
} U.S.A.

\begin{abstract}
This work determined whether mineral dissolution due to prolonged testing or storage of bone specimens in normal saline would alter their elastic modulus. In one experiment, small pieces of equine third metacarpal bone were soaked in normal saline supplemented with varying amounts of $\mathrm{CaCl}_{2}$. Changing $\mathrm{Ca}$ ion concentrations in the bath were monitored and the equilibrium concentration was determined. In a second experiment, the elastic moduli of twenty $4 \times 10 \times 100 \mathrm{~mm}$ equine third metacarpal beams were determined non-destructively in four-point bending. Half the beams were then soaked for 10 days in normal saline, and the other half in saline buffered to the bone mineral equilibrium point with $\mathrm{Ca}$ ions. Modulus measurements were repeated at 6 and 10 days. The equilibrium $\mathrm{Ca}$ ion concentration for bone specimens was found to be $57.5 \mathrm{mg} 1^{-1}$. The modulus of bone specimens soaked in normal saline significantly diminished $2.4 \%$, whereas the modulus of those soaked in calcium-buffered saline did not change significantly.
\end{abstract}

\section{INTRODUCTION}

A common problem in biomechanics is the accurate measurement of the elastic modulus of bone. Often it is important to be able to detect small differences in modulus--for example, when studying the effects of a drug, or anisotropy effects. Another example would be in fatigue experiments designed to detect the gradual accrual of damage as manifested by changes in elastic modulus. Initially, at least, such changes are quite small. Thus, it is important to be able to measure the modulus as accurately as possible.

In order to simulate in vivo conditions, bone is often stored, and tests are done, in normal saline bath. Fatigue tests may require many hours or days of submersion in such a bath to accumulate the required number of load cycles. In our own fatigue experiments we became concerned that mineral would leach from the bone as it soaked in a saline solution containing no calcium or phosphate ions. Currey (1969) has shown that the elastic modulus of bone is quite sensitive to its mineral content. Also Walsh and Guzelsu (1994) have recently shown that the ionic content of storage baths can alter the mechanical properties of bone. We were therefore afraid that even a small amount of mineral lost to the bath would alter the elastic modulus of the specimens, confounding our attempts to determine the effects of fatigue damage on bone modulus. We therefore conducted experiments to test the following four hypotheses: (1) mineral will dissolve from bone specimens maintained for 7 days in normal $(0.9 \%)$ saline at room temperature without mechanical loading, (2) the loss of mineral will significantly reduce the elastic modulus of the bone, (3) an initial calcium ion concentration in the bath can be found such that no net dissolution from the bone will occur, and (4) buffering the saline bath with calcium will retard mineral dissolution so as to maintain the elastic modulus over a 10 day period.

\section{METHODS}

Experiment 1 tested the hypothesis that calcium will leach from bone when soaked in normal saline. It also sought the solution equilibrium concentration of $\mathrm{Ca}^{2+}$ which would prevent loss of calcium from the bone. Using a Gillings-Hamco diamond blade saw, 'chips' measuring approximately $7.5 \times$ $7.5 \times 3 \mathrm{~mm}$ were cut from the diaphyses of freshly frozen third metacarpal (cannon) bones of several racehorses. These were dried at $100^{\circ} \mathrm{C}$ for $24 \mathrm{~h}$ and weighed. Approximately $8 \mathrm{~g}$ of dried chips were placed with $40 \mathrm{ml}$ of normal saline in each of nine glass jars. The saline in the jars was supplemented with calcium chloride $\left(\mathrm{CaCl}_{2}\right)$ to produce nine different $\mathrm{Ca}^{2+}$ concentrations $\left[\mathrm{Ca}^{2+}\right]$, ranging from 0 to $500 \mathrm{mgl}^{-1}$. Each jar was maintained at room temperature and continuously stirred. Each had a screw-on cap to prevent evaporation and to inhibit $\mathrm{CaCO}_{3}$ formation due to $\mathrm{CO}_{2}$ in the air. $\left[\mathrm{Ca}^{2+}\right]$ in the solutions were measured daily with an Orion calcium electrode. Prior to taking measurements, the electrode was calibrated against a set of standard saline solutions containing $\left[\mathrm{Ca}^{2+}\right]$ ranging from 0.2 to $2000 \mathrm{mgl}^{-1}$. Plateauing of $\left[\mathrm{Ca}^{2+}\right]$ vs time plots showed the point at which each solution had reached its equilibrium (Fig. 1). To find the starting $\left[\mathrm{Ca}^{2+}\right]$ that would lead to no net change in $\left[\mathrm{Ca}^{2+}\right]$, the difference in starting to ending $\left[\mathrm{Ca}^{2+}\right]$ was calculated for each solution. These points were then plotted against initial $\left[\mathrm{Ca}^{2+}\right]$, and a linear regression was fitted.

In Experiment 2, beams measuring $4 \times 10 \times 100 \mathrm{~mm}$ were machined from cannon bones of five race horses (three geldings, one stud, one mare), 3-7 yr old. Twenty such beams were taken from the cortical portion of the dorsal (7), medial (6), and lateral (7) 


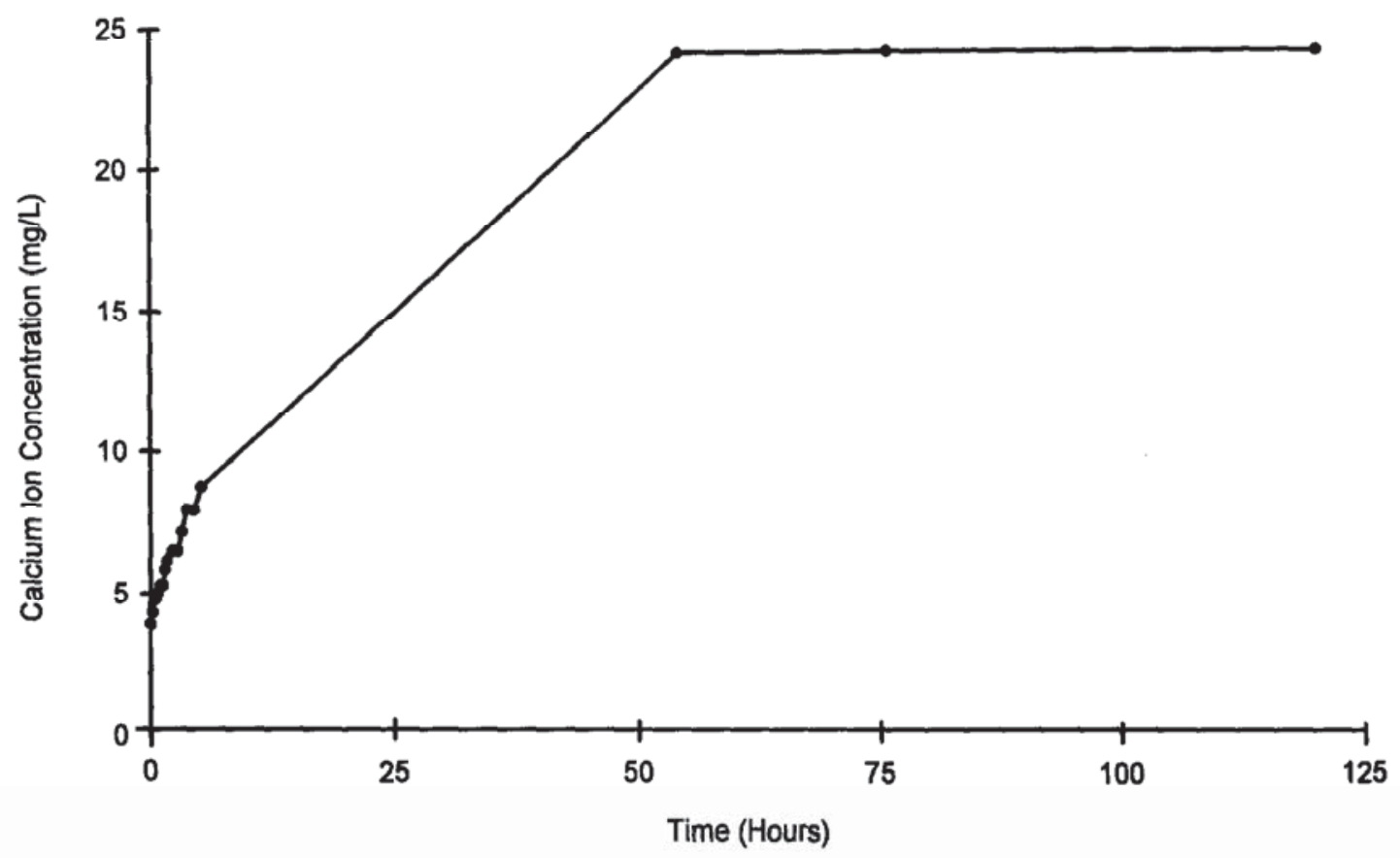

Fig. 1. Calcium ion concentration in the bath vs time for Experiment 1 . The normal saline bath initially started with no calcium ions. Calcium dissolved from the bone until the solution reached equilibrium, as shown by the plateau. Similar relationships were seen for the remaining eight non-zero initial calcium concentrations. Concentrations starting below the equilibrium $\left[\mathrm{Ca}^{2+}\right]$ of $57.5 \mathrm{mg}^{-1}$ rose asymptotically, and those initially above $57.5 \mathrm{mg}^{-1}$ decreased to a plateau.

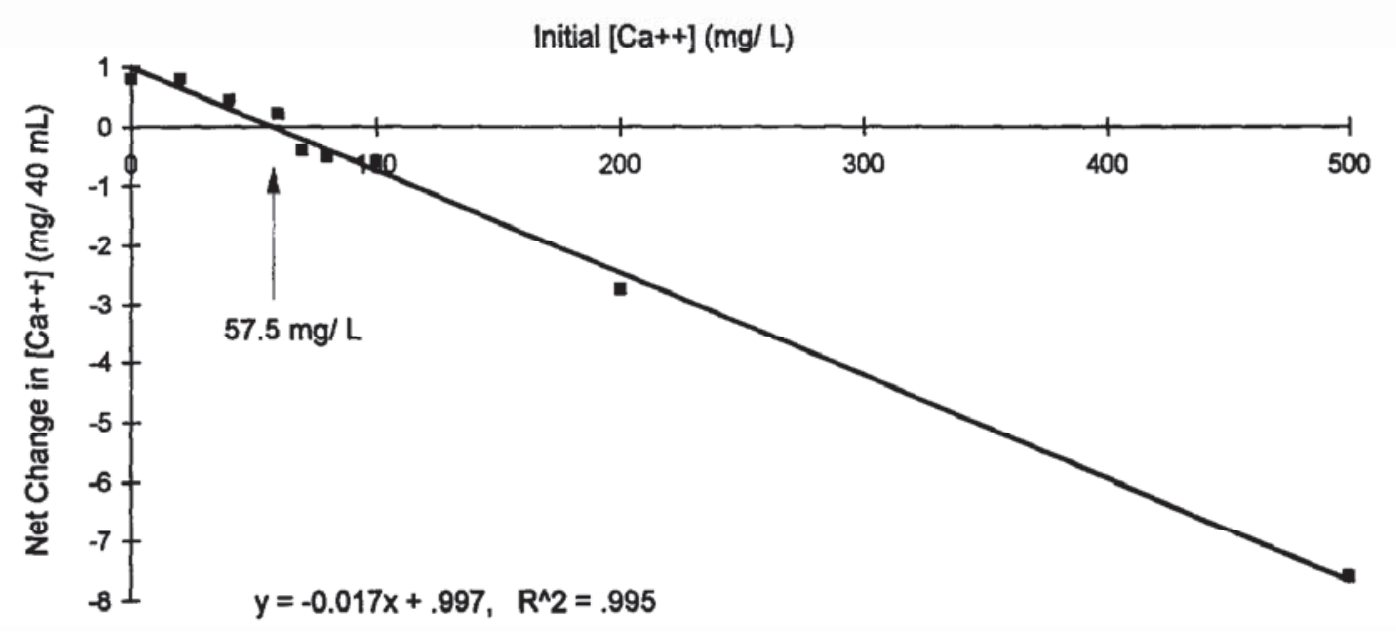

Fig. 2. Plot of net change in calcium ion concentration versus the initial concentration for Experiment 1. A positive net change occurred when the solution initally had less than the equilibrium $\mathrm{Ca}^{2+}$ ion level, and vice versa. The regression equation through these points was used to calculate the equilibrium value indicated by the $x$-axis intercept: $57.5 \mathrm{mgl}^{-1}$.

regions of the diaphysis. The original bones and then the machined beams were wrapped in saline-soaked paper towels, placed inside plastic bags, and stored frozen at $-4^{\circ} \mathrm{C}$ until tested. Each beam was cyclically tested non-destructively in four point bending using ASTM Standard D790M-82 to determine its initial elastic modulus. The inner and outer supports were 32 and $64 \mathrm{~mm}$ apart, respectively, and testing was done at $37^{\circ} \mathrm{C}$ in a saline bath. The MTS servohydraulic testing machine sinusoidally loaded each beam 10 times between 10 and $80 \mathrm{~N}$ at a frequency of $2 \mathrm{~Hz}$. The mean slope, $m$, of the 10 load- deformation tests (as calculated by linear regression on each one) was used in the equation $E_{\mathrm{B}}=\left(0.17 L^{3} \mathrm{~m}\right) /\left(b d^{3}\right)$ to find the beam's elastic modulus. Here, $L$ is the outer support length, and $b$ and $d$ are the beam's width and depth, respectively.

The specimens were then randomly divided into two groups of ten beams each. The Ca-free group was soaked in 191 of normal saline supplemented with $0.01 \%$ sodium azide to avoid collagen degradation by bacterially formed enzymes. The Ca-buffered group was soaked in 191 of a similar solution, except it was buffered with $\mathrm{CaCl}_{2}$ to produce $\mathrm{a} \mathrm{Ca}^{2+}$ concentration equal to 
the equilibrium value determined in Experiment 1. In both cases, the solutions were kept at room temperature and continuously stirred with a magnetic stir bar. After 6 days, the beams were removed from their baths and their elastic moduli were remeasured at $37^{\circ} \mathrm{C}$ in unbuffered saline using the same procedure as before. They were then returned to their respective room-temperature solutions for $\mathbf{4}$ more days, after which final modulus measurements were made, again at $37^{\circ} \mathrm{C}$. A repeated measures, two factor analysis of variance was used to test for significant changes in the elastic modulus of the beams as they were soaked in the two kinds of baths: saline alone or saline buffered with calcium.

\section{RESULTS}

In Experiment 1, when the initial value of $\left[\mathrm{Ca}^{2+}\right]$ was low, $\left[\mathrm{Ca}^{2+}\right]$ increased and asymptotically approached an equilibrium level (Fig. 1). Conversely, $\left[\mathrm{Ca}^{2+}\right]$ decreased to a plateau in the solutions initially containing excessive calcium. These data were used to find the net change in $\left[\mathrm{Ca}^{2+}\right]$ from the initial value of the equilibrium value for each of the nine initial calcium concentrations. When the change in $\left[\mathrm{Ca}^{2+}\right]$ between the initial and equilibrium values was plotted as a function of the initial calcium ion concentration, a linear relationship was seen (Fig. 2). The intercept of the linear regression line through these data with the initial $\left[\mathrm{Ca}^{2+}\right.$ ] axis was $57.5 \mathrm{mg} \mathrm{l}^{-1}$; this was taken as the equilibrium concentration for the bone-saline system. That is, if bone specimens were placed in a saline solution containing this concentration of calcium ions, no net change in $\left[\mathrm{Ca}^{2+}\right]$ would be expected because the precipitation and dissolution of $\mathrm{Ca}$ ions would be balanced.

In Experiment 2, there was no statistically significant difference between the initial elastic moduli of the two groups of beams $(p=0.7$, Table 1). Repeated measures analysis of variance showed that when the beams were soaked in normal saline alone, the elastic modulus significantly decreased after 6 days ( $p=0.011$, Fig. 3). The mean change was $2.4 \%$. There was no further diminishment at the end of the 10 day experiment. The calcium ion concentration in the bath increased monotonically without plateauing. When the beams were soaked in calciumbuffered saline, there was no change in elastic modulus, even
Table 1. Effects of Ca buffering on repeated elastic modulus measurements, $\mathrm{GPa}^{*}$

\begin{tabular}{lcc}
\hline Time & \multicolumn{2}{c}{ Bath } \\
\cline { 2 - 3 } & Normal saline & Ca-Buffered saline \\
\hline Day 0 & $18.7 \pm 0.8$ & $19.1 \pm 0.5$ \\
Day 6 & $18.3 \pm 0.7$ & $19.3 \pm 0.5$ \\
Day 10 & $18.2 \pm 0.7$ & $19.2 \pm 0.6$ \\
\hline
\end{tabular}

* Mean \pm standard error of the mean, 10 specimens in each column.

over the 10 day period $(p=0.514) .\left[\mathrm{Ca}^{2+}\right]$ in the bath increased slightly the first two days, then remained constant for the duration of the experiment.

\section{DISCUSSION}

The experiments supported each of the stated hypotheses. We showed that calcium ions will dissolve from small bone specimens in a saline bath at room temperature and that buffering the saline with calcium will control this dissolution. We also showed that the elastic modulus diminished approximately $2.4 \%$ when exposed to an unbuffered saline bath for 6 days and that the modulus did not change while in a calcium buffered bath.

One limitation of this study is that the specimens in Experiment 1 were not controlled for gender, age, or region in the diaphysis. We do not know how these factors might affect the equilibrium $\left[\mathrm{Ca}^{2+}\right]$. However, it can be noted that the equilibrium concentration which we measured, $57.5 \mathrm{mgl}^{-1}$, is within the range of ionized $\mathrm{Ca}$ concentrations in horse serum. The range for total calcium is $10.9-12.8 \mathrm{mg} \mathrm{dl}^{-1}$ (Probst and Parry, 1987). Assuming that $50 \%$ of this is ionized, the range of ionized calcium concentration would be $54.5-64.0 \mathrm{mg} \mathrm{l}^{-1}$.

A second limitation was that the soaking portions of our experiments were done at room temperature. The effects would be expected to increase if the bath were maintained at body temperature, as in a fatigue test. Another limitation was that the

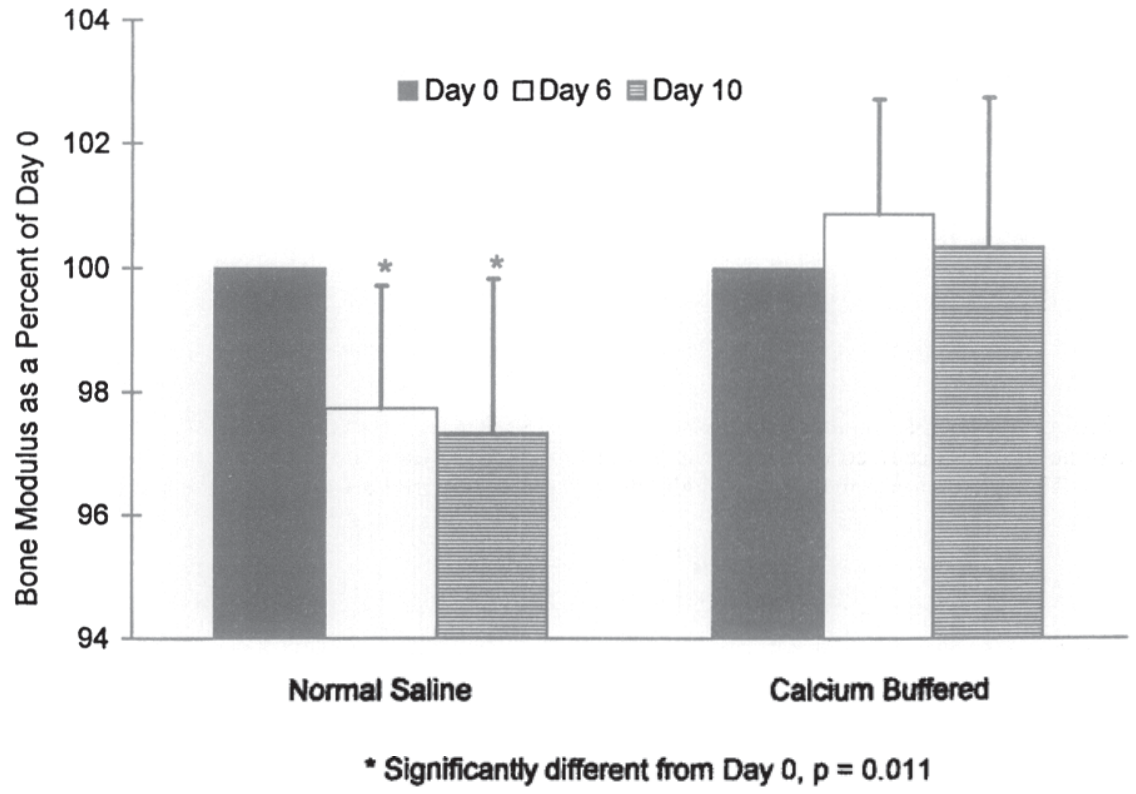

Fig. 3. The effects of soaking equine beams in saline for 6 or 10 days are shown relative to the initial value $(100 \%$ on Day 0$)$. When normal saline alone was used, the values measured after 6 and 10 days are significantly different than the initial value, but not different from each other. When $57.5 \mathrm{mgl}^{-1}$ of Ca $^{2 \text { - }}$ ions were added to the saline, there was no change in modulus at either time point. 
baths were not supplemented with phosphate ions, only $\mathrm{Ca}^{2+}$. Presumably, when placed in normal saline, bone will lose both kinds of ions as its calcium phosphate dissolves. Nevertheless, buffering with only the calcium ion species prevented modulus diminishment. This simplifies the problem of avoiding calcium leaching during mechanical testing.

Clearly, some fatigue tests may last only a few hours, and not require calcium buffering. However, fatigue experiments done at physiologic strains, and thus of greater clinical interest, would last longer and thus be more likely to require buffering. We did not determine the minimum time in saline to produce a significant modulus reduction, nor did we determine the volume of saline that would saturate with calcium before a significant loss of modulus had occurred. Therefore, and for the sake of uniformity, it might be best to conduct all fatigue tests in calcium-buffered saline.

It is also important to realize that the loss of material from the bone was probably not at all homogeneous. Typically, when bone specimens are demineralized for histologic purposes, radiographs reveal that mineral is preferentially lost from the external surfaces, which are in contact with the acidic bath. If this was true in our experiments as well, the effect would change the bending modulus of the specimens more than the uniaxial modulus because much of the removed mineral would be far from the neutral axis. The modulus measured after calcium leaching was thus an effective modulus for an inhomogeneous beam. Clearly, specimen size and porosity would also affect both the rate and inhomogeneity of calcium leaching. Histomorphometric structure may also be important.

The effects of embalming and other means of storing bone on its mechanical properties have been studied by several investigators (McElhaney et al., 1964; Sedlin, 1965), but we have only found two papers which explored the effects of storage in saline on mechanical properties. Walsh and Guzelsu (1994) found that cortical bone specimens stored for $72 \mathrm{~h}$ in saline to which phosphate or fluoride had been added gained or lost stiffness, respectively, compared to controls stored in saline alone. However, they did not test for the effects of $72 \mathrm{~h}$ storage in saline alone. Linde and Sorensen (1993) found that trabecular bone stored for $24 \mathrm{~h}$ in physiological saline experienced a $10 \%$ drop in modulus.
However, they attributed this change to time-after-death. Black (1984) has reviewed the literature of post-mortem changes in mechanical properties, but there do not seem to be any studies which have tried to distinguish between the effects of storage in saline and the effects of post-mortem time. Since our specimens had been stored in a frozen state for weeks before the experiment, we believe that the effects we saw were unlikely to be due to post-mortem changes.

Acknowledgments--This work was supported by NIH Grant no. AR41644. We also gratefully acknowledge the assistance of the Hearst Foundation, Mr and Mrs Amory J. Cooke, the California Horse Racing Board Postmortem program, and the Equine Research Laboratory, University of California, Davis, the Oak Tree Racing Association, the State of California satellite wagering fund, and contributions by private donors.

\section{REFERENCES}

Black, J. (1984) Tissue properties: relationship of in vitro studies to in vivo behavior. In Natural and Living Biomaterials (Edited by Hastings, G. W. and Ducheyne, P.), pp. 5-26. CRC Press, Boca Raton, FL.

Currey, J. D. (1969) The mechanical consequences of variation in the mineral content of bone. J. Biomechanics 2, 1-11.

Linde, F. and Sorensen, H. C. F. (1993) The effect of different storage methods on the mechanical properties of trabecular bone. J. Biomechanics 26, 1249-1252.

McElhaney, J. H., Fogle, J., Byars, E. and Weaver, G. (1964) Effect of embalming on the mechanical properties of beef bone. J. Appl. Physiol. 19, 1234-1236.

Probst, D. F. and Parry, B. W. (1987) Normal clinical pathology data. In Current Therapy in Equine Medicine (Edited by Robinson, N. E.), pp. 725-729. W. B. Saunders, Philadelphia. Sedlin, E. D. (1965) A rheological model for cortical bone. Acta Orthop. Scand. 83, 1-78.

Walsh, W. R. and Guzelsu, N. (1994) Compressive properties of cortical bone: mineral-organic interfacial bonding. Biomaterials 15, 137-145. 